\title{
RNA-Guided RNA modification: functional organization of the archaeal H/ACA RNP
}

\author{
Daniel L. Baker, ${ }^{1}$ Osama A. Youssef, ${ }^{1}$ Michael I.R. Chastkofsky, David A. Dy, Rebecca M. Terns, ${ }^{2}$ \\ and Michael P. Terns ${ }^{3}$
}

Department of Biochemistry and Molecular Biology, University of Georgia, Athens, Georgia 30602, USA

\begin{abstract}
In eukaryotes and archaea, uridines in various RNAs are converted to pseudouridines by RNA-guided RNA modification complexes termed H/ACA RNPs. Guide RNAs within the complexes base-pair with target RNAs to direct modification of specific ribonucleotides. Cbf5, a protein component of the complex, likely catalyzes the modification. However, little is known about the organization of H/ACA RNPs and the roles of the multiple proteins thought to comprise the complexes. We have reconstituted functional archaeal H/ACA RNPs from recombinant components, defined the components necessary and sufficient for function, and determined the direct RNA-protein and protein-protein interactions that occur between the components. The results provide substantial insight into the functional organization of this RNP. The functional complex requires a guide RNA and each of four proteins: Cbf5, Gar1, L7Ae, and Nop10. Two proteins interact directly with the guide RNA: L7Ae and Cbf5. L7Ae does not interact with other H/ACA RNP proteins in the absence of the RNA. We have defined two novel functions for Cbf5. Cbf5 is the protein that specifically recognizes and binds H/ACA guide RNAs. In addition, Cbf5 recruits the two other essential proteins, Gar1 and Nop10, to the pseudouridylation guide complex.
\end{abstract}

[Keywords: Noncoding RNA; RNA modification; RNA-protein complex; archaea; pseudouridylation]

Supplemental material is available at http://www.genesdev.org.

Received February 24, 2005; revised version accepted April 1, 2005.

The two most extensive classes of noncoding RNAs are microRNAs (or siRNAs) and modification guide RNAs. MicroRNAs regulate protein production by base-pairing with target mRNAs and triggering destruction or inhibition of translation (Ambros 2004; Bartel 2004; He and Hannon 2004). Similarly, modification guide RNAs basepair to target RNAs, in this case effecting modification of targeted nucleotides (Kiss 2002; Decatur and Fournier 2003). The RNA-guided RNA modification system alters the primary sequence and modulates the function of target RNAs that include rRNAs, snRNAs, tRNAs, and perhaps mRNAs (Yu et al. 1998, 2005; Cavaille et al. 2000; King et al. 2003; Omer et al. 2003). In humans it is currently estimated that $>200$ 2'-O-methylations and pseudouridylations are introduced into rRNA and other RNAs by this system (Maden 1990; Bachellerie and Cavaille 1998; Ofengand and Fournier 1998; Vitali et al. 2003).

\footnotetext{
${ }^{1}$ These authors contributed equally to this work. Corresponding authors.

${ }^{2}$ E-MAIL rterns@bmb.uga.edu; FAX (706) 542-1752.

${ }^{3}$ E-MAIL mterns@bmb.uga.edu; FAX (706) 542-1752.

Article published online ahead of print. Article and publication date are

at http://www.genesdev.org/cgi/doi/10.1101/gad.1309605.
}

There are two large families of modification guide RNAs found in both eukaryotes and archaea: C/D RNAs that guide 2'-O-ribose methylation (Kiss-Laszlo et al. 1996; Omer et al. 2000) and H/ACA RNAs that guide pseudouridylation (Balakin et al. 1996; Ganot et al. 1997a,b; Tang et al. 2002). Both families of guide RNAs function in the context of RNA-protein complexes (RNPs) that include the enzyme responsible for modification (Filipowicz and Pogacic 2002; Terns and Terns 2002). The functional organization of modification guide RNPs, including the mechanism by which the enzyme associates with a guide RNA and the roles of the other essential proteins in the complex, is a subject of great interest. In C/D RNPs the 2'-O-methyltransferase, fibrillarin, associates with a guide RNA primarily via a bridge formed by the other proteins in the complex, Nop56/58 and L7Ae (or Nop56, Nop58, and p15.5 in eukaryotes). L7Ae binds directly to box C/D RNAs via Kink (K)-turn motifs (Klein et al. 2001) formed by conserved box $\mathrm{C}$ and box D sequences (Watkins et al. 2000; Kuhn et al. 2002; Charron et al. 2004), and thereby nucleates assembly of the RNP. Binding of L7Ae mediates binding of Nop56/ 58 , which in turn allows association of fibrillarin with the guide RNA (Omer et al. 2002; Aittaleb et al. 2003; Rashid et al. 2003; Tran et al. 2003). Base-pairing of the 
guide RNA with the target RNA positions the substrate nucleotide for 2'-O-methylation by fibrillarin (Cavaille et al. 1996; Kiss-Laszlo et al. 1996).

Much less is known about the structure and function of the pseudouridylation guide RNPs or H/ACA RNPs. Four proteins have been identified as components of H/ACA RNPs: Cbf5, Gar1, L7Ae (Nhp2 in eukaryotes), and Nop10 (Bousquet-Antonelli et al. 1997; Henras et al. 1998; Lafontaine et al. 1998; Watkins et al. 1998; Dragon et al. 2000; Watanabe and Gray 2000; Rozhdestvensky et al. 2003). In yeast, these proteins are found associated with H/ACA guide RNAs, and disruption of the corresponding genes affects pseudouridylation (BousquetAntonelli et al. 1997; Henras et al. 1998; Lafontaine et al. 1998; Watkins et al. 1998). The sequence and structure of Cbf5 suggest that it is a pseudouridine synthase (Koonin 1996; Lafontaine et al. 1998; Zebarjadian et al. 1999; Charette and Gray 2000; Hoang and Ferre-D'Amare 2001). The precise roles of the other proteins are not known. It is not known whether these four proteins comprise the full set of proteins required for RNA-guided pseudouridylation. It is also not known whether the essential roles of the proteins in vivo reflect direct involvement in modification or critical upstream functions (e.g., stabilization or trafficking of guide RNAs). The pseudouridylation guide RNAs are comprised of one to three hairpins, each of which contains a bipartite guide sequence within an internal loop (pseudouridylation pocket) and is followed by a conserved sequence element, either box $\mathrm{H}$ or box ACA (see Fig. 1A; Balakin et al. 1996; Ganot et al. 1997b; Tang et al. 2002). Due largely to the technical difficulties that have been encountered with the protein components of H/ACA RNPs from eukaryotes, there is very little information about the organization and composition of functional complexes.

In this work we report the first reconstitution of RNAguided RNA pseudouridylation from recombinant components. We have reconstituted functional H/ACA RNPs using components from the hyperthermophilic archaeon Pyrococcus furiosus. Our results demonstrate that each of four proteins, Cbf5, Gar1, L7Ae, and Nop10, and the guide RNA are essential, and that this set of five components is sufficient for function in vitro. The reaction depends upon the pseudouridylation pocket, K-turn, and box ACA sequence within the guide RNA. We have also mapped the direct RNA-protein and protein-protein interactions between the components of the archaeal pseudouridylation guide complex. Surprisingly, we have found that Cbf5, the presumptive pseudouridine synthase, interacts directly and specifically with the H/ACA guide RNA. The interaction of Cbf5 with the guide RNA depends on the signature motif, box ACA, and the pseudouridylation pocket (and also to some extent on sequences in the terminal loop of the hairpin), but does not depend on the K-turn. In addition, the archaeal Cbf5 protein can specifically recognize eukaryotic H/ACA RNAs. Our results suggest that the number of molecules of Cbf5 bound to an H/ACA RNA correlates with the number of RNA hairpin units. As has been reported previ-
A

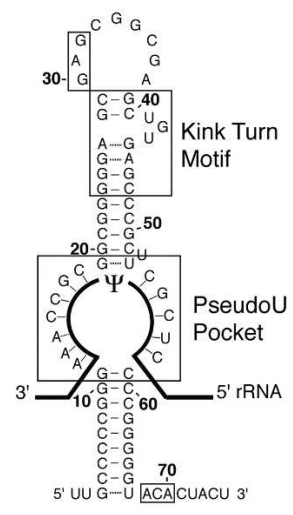

C

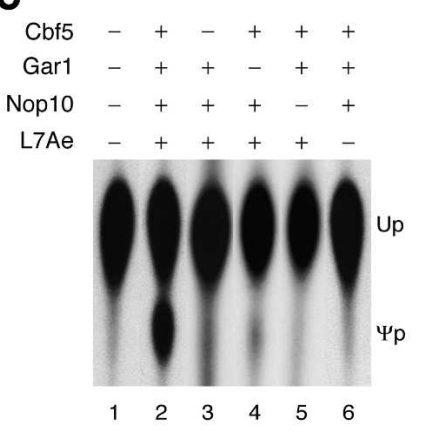

B

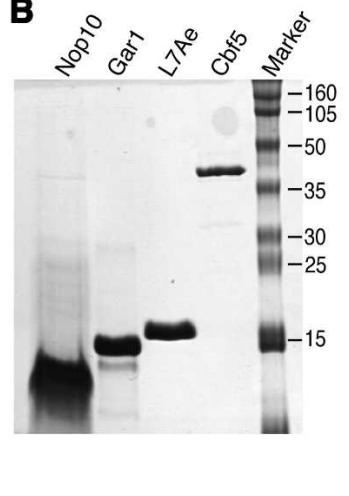

D

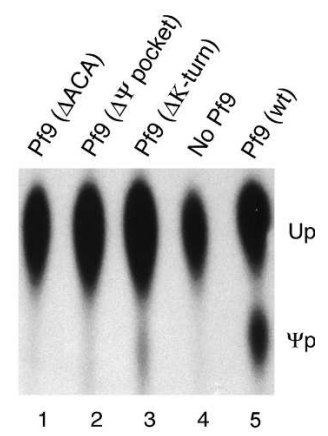

Figure 1. Reconstitution of functional pseudouridylation guide RNPs from recombinant RNA and protein components. (A) Sequence and secondary structure of Pf9 H/ACA guide RNA with important elements indicated. Box ACA is located at the base of the hairpin structure near the $3^{\prime}$ end of the RNA (nucleotides 68-70). The pseudouridylation pocket is an internal loop bounded by the upper and lower stems of the hairpin. The nucleotides within the pocket base-pair with the rRNA substrate (represented as solid bold line), positioning the unpaired uridine to be modified $(\Psi)$ at the top of the loop. A kink-turn motif is located in the upper stem, near the terminal loop of the hairpin and consists of an asymmetric loop containing two G-A base pairs and flanked by two short stems (Klein et al. 2001). A GAG sequence present in the terminal loop of Pf9 and other archaeal H/ACA RNAs is indicated (nucleotides 30-32). (B) Purified samples of H/ACA RNP proteins Cbf5, Gar1, Nop10, and L7Ae analyzed by SDS PAGE and Coomassie protein staining are shown. $(C)$ Pseudouridylation activity of various combinations of the four recombinant H/ACA RNP proteins. Pf9 guide RNA and substrate RNA (containing a single, ${ }^{32} \mathrm{P}$-labeled target uridine) were incubated with the indicated combinations of proteins. Pseudouridylation was assessed by TLC separation of nucleotides (obtained by nuclease P1 digestion of RNA) under established conditions where pseudouridine $(\Psi \mathrm{p})$ migrates more slowly than uridine (Up) (Yu et al. 2001). Autoradiographs of TLC plates are shown. $(D)$ Effect of mutations in Pf9 guide RNA on pseudouridylation activity. Box ACA was mutated to UGU ( $\triangle \mathrm{ACA})$. Pseudouridylation pocket was eliminated by replacement of sequence on one side of the loop with sequence complementary to other side of the loop ( $\Delta \Psi$ pocket). The K-turn was mutated by disruption of critical GA base pairs (substitution of GA with CC; $\Delta \mathrm{K}$-turn). The indicated mutant or wild-type Pf9 guide RNA was incubated with the four recombinant proteins and substrate RNA, and pseudouridylation activity was assessed as in $C$. 
ously (Rozhdestvensky et al. 2003), L7Ae also interacts directly with the H/ACA RNA via the K-turn. Our work indicates that L7Ae does not interact independently with the other protein components of the RNP and also is not required for the interaction of the other proteins with the guide RNA. The other two essential proteins, Garl and Nop10, do not interact with the guide RNA in the absence of other proteins. We have found that Garl and Nop10 each interact independently with Cbf5, which mediates the association of these two proteins with the H/ACA guide RNA.

\section{Results}

Requirements for RNA-guided RNA pseudouridylation

Proteins with sequence homology to the four proteins associated with eukaryotic pseudouridylation guide RNPs are encoded in archaeal genomes, but with the exception of $\mathrm{L} 7 \mathrm{Ae}$, these proteins have not been characterized (Watanabe and Gray 2000; Rozhdestvensky et al. 2003). In order to assess the potential role of the four archaeal proteins in RNA-guided pseudouridylation, we investigated whether a functional RNP complex could be reconstituted in vitro using proteins and RNAs from P. furiosus.

We used Pf9, a single hairpin H/ACA RNA from $P$. furiosus, as the guide RNA for the majority of our work. Pf9 was identified as a potential noncoding RNA by Klein et al. (2002) in a computational screen for GCrich regions in the AT-rich genomes of hyperthermophilic archaea. We have determined that this RNA is an H/ACA RNA (see Fig. 1A) and verified the corresponding modification at the predicted target site (U910) in P. furiosus 16S rRNA (S. Marshburn, R. Terns, and M. Terns, unpubl.). The four predicted $P$. furiosus H/ACA RNP proteins (Cbf5, L7Ae, Garl, and Nop10) were expressed with histidine tags and purified by affinity chromatography (Fig. 1B). The substrate for the pseudouridylation assay consisted of the target region of $P$. furiosus $16 \mathrm{~S}$ rRNA (nucleotides 905-917) flanked by three nucleotide extensions at each end. In addition, to facilitate unequivocal interpretation of results we substituted three of the uridines that base-pair with Pf9 (nucleotides 915917) with adenines (and made compensatory changes in the sequence of the pseudouridylation pocket of Pf9) to eliminate uridines other than the target uridine from the substrate for this assay. (When transcribed in the presence of radiolabeled UTP, the substrate RNA will be labeled only at the target uridine.)

We incubated the radiolabeled substrate RNA with unlabeled Pf9 guide RNA and various combinations of the four purified proteins (Fig. 1C). To test for pseudouridylation of the substrate, we extracted and nucleasedigested the RNA, separated uridines and pseudouridines by thin layer chromatography, and examined the products by autoradiography. No pseudouridylation was observed in the absence of proteins (Fig. 1C, lane 1) or in the absence of Pf9 RNA (Fig. 1D, lane 4). In addition, no single protein, including the pseudouridine syn- thase Cbf5, was found to catalyze pseudouridylation of the rRNA substrate (data not shown). However, pseudouridylation was observed upon addition of all four proteins and the guide RNA (Fig. 1C, lane 2). Importantly, the absence of any one protein from the reaction resulted in substantial loss or elimination of pseudouridylation activity (Fig. 1C, lanes 3-6). The results indicate that these four proteins, which were implicated in RNAguided pseudouridylation on the basis of homology to eukaryotic H/ACA RNP proteins, function in this process in $P$. furiosus. Moreover, our results demonstrate for the first time that the activity of an H/ACA guide RNP depends on all four proteins, Cbf5, Gar1, Nop10, and L7Ae, as well as the guide RNA in vitro.

We then tested the importance of conserved elements of the guide RNA in function (Fig. 1D). We incubated the substrate RNA with the four proteins and various Pf9 mutant RNAs. Disruption of box ACA, the pseudouridylation pocket, or the K-turn eliminated or severely reduced function (Fig. 1D, cf. lanes 1-3 and 5). Thus, function of the complex in vitro also depends on at least three important elements of the guide RNA: the signature motif (box ACA), the pseudouridylation pocket, and the L7Ae-binding site (K-turn) (see Rozhdestvensky et al. 2003).

\section{Mechanism of association of Cbf5 with H/ACA guide RNAs}

One key issue is the mechanism by which the enzyme (Cbf5) associates with the guide RNAs. In the case of C/D modification guide RNPs, it is clear that the association of the enzyme (fibrillarin) depends on prior binding of the other protein components of the RNP /Omer et al. 2002; Rashid et al. 2003; Tran et al. 2003). Interestingly, the protein that recognizes C/D RNAs and initiates assembly of the $\mathrm{C} / \mathrm{D}$ complex is a common component of C/D and H/ACA RNPs in archaea: L7Ae (Kuhn et al. 2002; Rozhdestvensky et al. 2003). Furthermore, L7Ae has also been shown to bind directly to archaeal H/ACA RNAs via K-turns (Rozhdestvensky et al. 2003). Therefore it seemed likely that L7Ae might also be involved in the assembly of the H/ACA proteins on H/ACA RNAs in archaea.

We tested the ability of each of the four H/ACA RNP proteins to interact with the H/ACA guide RNA (Pf9) in the absence of the other proteins by gel mobility shift assay (Fig. 2A). Consistent with a previous study (Rozhdestvensky et al. 2003), we found that L7Ae interacts with Pf9 and that the interaction depends on the K-turn motif of the RNA (Fig. 2A,B). Surprisingly however, we found that Cbf5 also interacts with Pf9 in the absence of the other H/ACA RNP proteins. The apparent $\mathrm{K}_{\mathrm{d}}$ of the interaction between Cbf5 and Pf9 (estimated as the concentration of protein resulting in half-maximal binding of the input RNA) was $\sim 450 \mathrm{nM}$ (Fig. 2C; data not shown). Cbf5 failed to interact with $P$. furiosus $\mathrm{C} / \mathrm{D}$

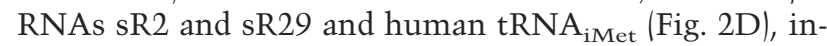
dicating that the direct interaction of Cbf5 with the guide RNA is specific. Finally, we found that Nop10 


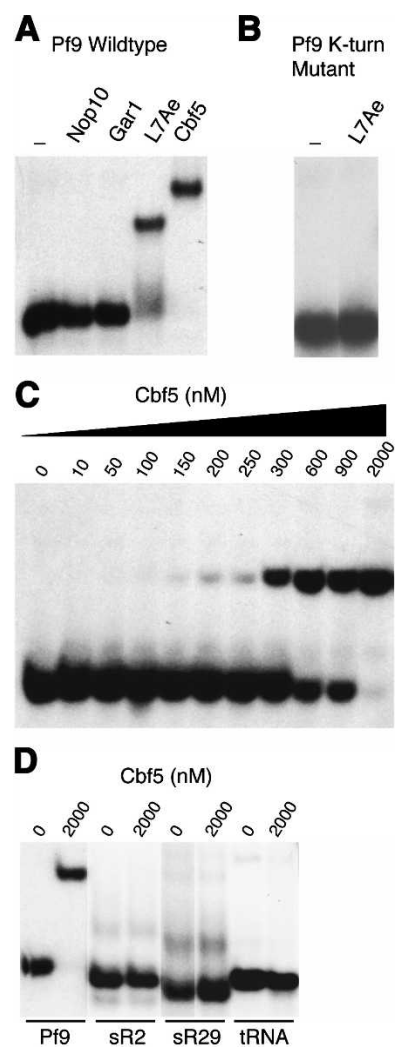

Figure 2. Cbf5 interacts directly and specifically with Pf9 $\mathrm{H} / \mathrm{ACA}$ guide RNA. Direct interactions of proteins with ${ }^{32} \mathrm{P}$ labeled RNAs were investigated by native gel mobility shift analysis and autoradiography. (A) Pf9 RNA was incubated with each of the four recombinant H/ACA RNP proteins or no protein $(-)$. (B) The K-turn of Pf9 was disrupted and the mutant RNA was incubated with L7Ae. $(C)$ Wild-type Pf9 was incubated with increasing concentrations of Cbf5 $(0-2000 \mathrm{nM})$ to assess the apparent $\mathrm{K}_{\mathrm{d}}$ of the observed interaction. (D) Cbf5 was incubated with non-H/ACA RNAs including $P$. furiosus C/D RNAs sR2 and sR29 and a human tRNA to assess the specificity of the observed interaction.

and Garl do not interact with the guide RNA independently (tested over a range of protein concentrations up to $600 \mathrm{nM}$ and $10 \mu \mathrm{M}$, respectively; data not shown). These results indicate that both the pseudouridine synthase Cbf5 and L7Ae interact directly with the guide RNA, but that the interactions of Garl and Nop10 with the guide RNA are likely mediated by the other proteins.

To identify the elements of the guide RNA that are important for its recognition by the modifying enzyme, we tested a series of Pf9 mutants and fragments in gel mobility shift assays (Fig. 3). We found that box ACA is essential, but not sufficient, for recognition by Cbf5. Mutation of box ACA eliminated the interaction observed with wild-type Pf9 (Fig. 3B). However, an RNA comprised of box ACA and the lower stem of the Pf9 hairpin was not sufficient for Cbf5 binding (Fig. 3C). The pseudouridylation pocket also plays an important role in the interaction of Cbf5 with Pf9. Addition of the pseudouridylation pocket to the lower stem and box ACA re- sulted in significant binding by Cbf5 (Fig. 3D). In addition, the elimination of the pseudouridylation pocket in the context of the full-length Pf9 RNA substantially reduced the ability of Cbf5 to interact with the guide RNA (Fig. 3E). However, while box ACA and the pseudouridylation pocket are necessary for recognition by Cbf5, it appears that these two are not the only elements that contribute to Cbf5 binding (Fig. 3D), and that another important element present in the upper region of the hairpin of the RNA is required for full binding activity. The K-turn is important for the interaction of L7Ae with Pf9 (Fig. 2B); however it is not essential for the interaction of Cbf5 (Fig. 3F). On the other hand, we found that replacement of the terminal loop of the hairpin with a stable tetra-loop significantly reduced binding (Fig. 3G). Although neither the sequence nor length of the terminal loops of H/ACA RNAs are thought to be conserved, we noticed a "GAG" sequence present within the terminal loop of several archaeal H/ACA sRNAs. (This bears some similarity to the $\mathrm{CAB}$ box that has been found to be important in the localization of certain guide RNAs to Cajal bodies in eukaryotes [Richard et al. 2003]). Mutation of the GAG sequence significantly reduced Cbf5 binding (Fig. $3 \mathrm{H}$ ), suggesting that this sequence within the terminal loop also plays a role in the interaction of Cbf5 with H/ACA guide RNAs.

We also examined the interaction of Cbf5 with other H/ACA RNAs in gel mobility shift assays. Pf3 is a double hairpin H/ACA RNA from $P$. furiosus (Klein et al. 2002; Rozhdestvensky et al. 2003). Interestingly, we found that Pf3 formed two distinct complexes with Cbf5 (Fig. 4A). The second complex (Fig. 4A, marked with ${ }^{\star \star}$ ), which comigrates with a band observed with RNA alone, appears with increasing concentrations of Cbf5. We did not observe the formation of more than one specific complex with the single hairpin RNA Pf9, even at protein concentrations up to $6 \mu \mathrm{M}$ (Fig. 2C; data not shown). The results suggest that Cbf5 interacts with each of the two hairpins of a double guide RNA. Mutation of the two ACA elements found in Pf3 disrupted the interaction of Cbf5 with Pf3 (Fig. 4B). In addition, we tested two types of eukaryotic H/ACA RNAs-a small nucleolar or snoRNA and a small Cajal body or scaRNA. U65 is a typical, human H/ACA snoRNA with two hairpins that guides rRNA modification in the nucleolus (Ganot et al. 1997b). U92 is a double hairpin H/ACA scaRNA that guides pseudouridylation of small nuclear (sn)RNA within Cajal bodies (Darzacq et al. 2002). P. furiosus Cbf5 formed two specific complexes with each of these human H/ACA RNAs (Fig. 4C,E). As is typical among eukaryotic H/ACA RNAs, a box $\mathrm{H}$ sequence (ANANNA) follows the $5^{\prime}$ hairpin in U65 and U92, and box ACA follows the 3' hairpin. Mutation of the ACA sequence associated with the $3^{\prime}$ hairpin disrupted the interaction of the archaeal Cbf5 with human U65 and U92 (Fig. $4 \mathrm{D}, \mathrm{F})$. The disruption of binding at both hairpins is consistent with the previous observation that mutation of either the $\mathrm{H}$ or ACA sequence element of a eukaryotic RNA eliminates the function of both guide elements (Bortolin et al. 1999) and suggests cooperativity in the 
Baker et al.

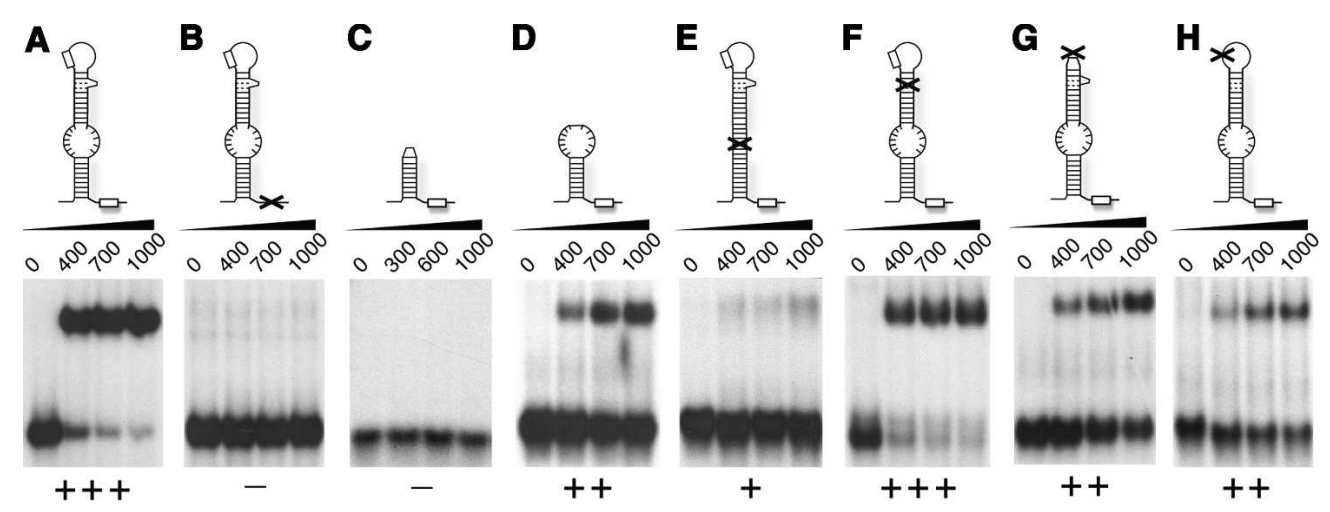

Figure 3. Elements of the H/ACA guide RNA important for Cbf5 interaction. The ability of Cbf5 to interact with mutants and fragments of Pf9 was assessed by native gel mobility shift analysis with a range of concentrations of Cbf5. Each panel shows a diagram of the RNA tested (location of mutations indicated with X), autoradiograph of gel shift analysis, and scaled estimate of the extent of interaction relative to wild-type Pf9 (- to +++). (A) Wild-type Pf9. (B) Mutation of box ACA (to UGU). (C) Deletion of the terminal loop, K-turn, upper stem, and pseudouridylation pocket. $(D)$ Deletion of the terminal loop, K-turn, and upper stem. $(E)$ Closure of pseudouridylation pocket by replacement of sequence on one side of the loop with sequence complementary to other side of the loop. $(F)$ Disruption of critical GA base pairs in K-turn by substitution of GA with CC. $(G)$ Replacement of terminal loop with tetra-loop. (H) Mutation of GAG in terminal loop (to CUC).

interaction of proteins with the two hairpins in eukaryotic double guide H/ACA RNAs.

In summary, these results indicate that Cbf5, the pseudouridine synthase, interacts with $\mathrm{H} / \mathrm{ACA}$ guide RNAs specifically and independently of the other proteins of the pseudouridylation guide complex. Our mutational analysis indicates that Cbf5 depends upon box ACA, the pseudouridylation pocket, and sequences within the terminal loop of the hairpin for interaction with the H/ACA RNA. Moreover, it appears that the number of molecules of Cbf5 that binds a guide RNA correlates with the number of hairpins.

\section{Protein-protein interactions within the archaeal $H / A C A R N P$}

Our results indicate that both Cbf5 and L7Ae interact directly and independently with H/ACA guide RNAs; however the means of association of Garl and Nop10 with the RNP was still unclear. In addition, we were very interested in identifying protein-protein interactions between components of the complex. We investigated the protein-protein interactions by incubating various combinations of the recombinant proteins (shown in input [I] lanes in Fig. 5), one of which was His-tagged (indicated with an asterisk in Fig. 5), and identifying the proteins associated with the tagged protein by affinity chromatography (shown in bound [B] lanes in Fig. 5). Bovine serum albumin (BSA) was included in all incubations to assess the extent of nonspecific interactions, but was not detected in the affinitypurified samples (Fig. 5). The results indicate that Cbf5 interacts directly with each Garl and Nop10 (Fig. 5, lanes 1-4). Gar1 and Nop10 do not interact with one another (Fig. 5, lanes 5,6), but Gar1 does copurify with tagged Nop10 in the presence of Cbf5 (Fig. 5, lanes $13,14)$, indicating that these three proteins form a heterotrimeric complex in which each Garl and Nop10 are bound to Cbf5. At the same time, no interaction was observed between L7Ae and either Gar1, Nop10, or Cbf5 (Fig. 5, lanes 7-12). Moreover, when all four proteins were coincubated, Cbf5, Gar1, and Nop10 copurified, but L7Ae did not, suggesting that L7Ae does not interact with the other protein components of the H/ACA RNP in the absence of the guide RNA (Fig. 5, lanes 15,16).

\section{In vitro assembly of an $H / A C A R N P$}

We next examined the assembly of the H/ACA RNP in gel mobility shift assays (Fig. 6). As we have shown, Cbf5 and L7Ae (but not Garl and Nop10) interact directly with the single hairpin guide RNA Pf9, and the interaction of Cbf5 with Pf9 depends on box ACA (Figs. 2, 3, 6 [lanes 1-5,10-14]). In protein-protein interaction assays we found that Garl and Nop10 interact with Cbf5 in the absence of the guide RNA (Fig. 5) and thus hypothesized that Cbf5 mediates the interaction of these two proteins with the RNP. Here we show that addition of each Nop10 and Gar1, and both Nop10 and Gar1 to Cbf5, in gel mobility shift assays results in stepwise supershifts of the RNA relative to Cbf5 alone (Fig. 6, lanes 4,6-8). Like the interaction of Cbf5 alone, these interactions are dependent on box ACA (Fig. 6, lanes 13,15-17). We did not observe a shift in the mobility of Pf9 with the combination of Gar1 and Nop10 in the absence of Cbf5 (data not shown). In addition, Gar1 and Nop10 did not supershift the L7Ae-Pf9 RNA complex (data not shown). These results indicate that $\mathrm{Cbf} 5$ mediates the interaction of both Garl and Nop10 with the H/ACA RNP. Addition of L7Ae resulted in a further supershift of the complex formed by Cbf5, Gar1, and Nop10 with Pf9 (Fig. 6, lane 9, asterisk), indicating that L7Ae can interact with Pf9 in the context of the complex formed with the other three proteins. Together, our results indicate that a functional H/ACA RNP is formed by the independent 
A
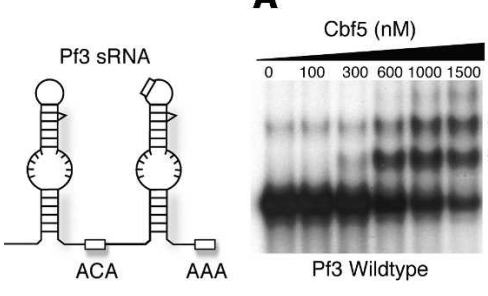

C
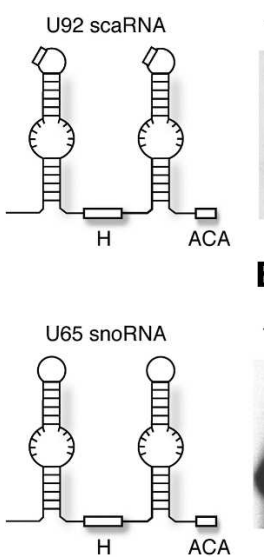

B

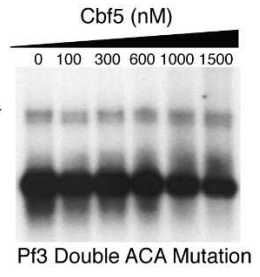

D

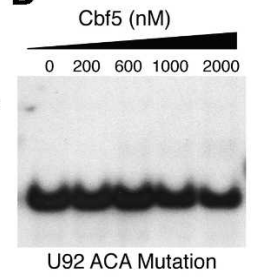

$\mathbf{F}$

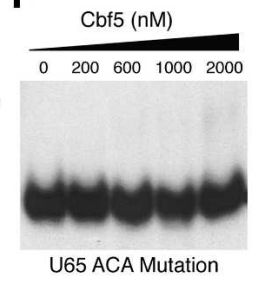

Figure 4. Cbf5 also interacts with archaeal and eukaryotic double hairpin H/ACA RNAs. $(A, C, E)$ The ability of Cbf5 to interact with double hairpin H/ACA RNAs Pf3 (a $P$. furiosus guide RNA), U92 (a eukaryotic scaRNA), and U65 (a eukaryotic snoRNA) was assessed by native gel mobility shift analysis with a range of concentrations of Cbf5. Distinct RNP complexes are indicated with single and double asterisks. A diagram of the RNA tested is shown to the left of each panel. $(B, D, F)$ In order to assess the specificity of the observed interactions and importance of box ACA, native gel mobility shift analysis was performed with RNAs in which the box ACA elements were mutated (ACA to UGU, or AAA to UUU in the case of the $3^{\prime}$ element of Pf3).

binding of each Cbf5 and L7Ae to distinct sites on the guide RNA and by independent binding of Garl and Nop10 to Cbf5.

\section{Discussion}

\section{RNA-guided RNA pseudouridylation}

Pseudouridylation is the most common RNA modification and occurs in tRNA, rRNA, snRNA, snoRNA, and likely other noncoding RNAs (Ofengand and Fournier 1998; Charette and Gray 2000; Yu et al. 2005). There is mounting evidence that pseudouridines occur in functionally important RNA domains and play a vital role in RNA-mediated cellular processes including pre-mRNA splicing and ribosome function (Yu et al. 1998; King et al. 2003; Donmez et al. 2004; Zhao and Yu 2004). Pseudouridylation of RNA is an evolutionarily ancient process catalyzed by a large family of enzymes known as pseudouridine synthases (Koonin 1996; Ofengand et al. 2001).

There are two distinct mechanisms by which pseudouridine synthases select target uridine residues for isom-

erization. In all known instances in eubacteria, pseudouridylations are carried out by dedicated pseudouridine synthases that each recognize one or a small set of similar RNA substrates (Koonin 1996; Charette and Gray 2000). Most known pseudouridine synthases are of this type. However, in archaea and eukaryotes, many pseudouridylations are introduced by RNA-guided pseudouridine synthases (Yu et al. 2005). The RNA-guided system is versatile and employs armies of H/ACA guide RNAs to direct a common pseudouridine synthase to many different sites. The RNA-guided pseudouridine synthases are members of the TruB subfamily and are called Cbf5(p) in yeast (Jiang et al. 1993) and archaea (Watanabe and Gray 2000), dyskerin in humans (Heiss et al. 1998), and NAP57 in rat (Meier and Blobel 1994). Three additional proteins are associated with the RNAguided pseudouridine synthases: Gar1, Nop10, and L7Ae (Nhp2 in eukaryotes). However, the roles of these additional proteins in pseudouridylation are not known. The results presented here provide a substantial amount of new information on the structure and function of the RNP that catalyzes RNA-guided RNA pseudouridylation in archaea.

The pseudouridine synthase Cbf5 interacts directly with H/ACA guide RNAs via the conserved box ACA element

Box ACA is the signature sequence element of H/ACA RNAs. In eukaryotes, mutational analysis has demon-
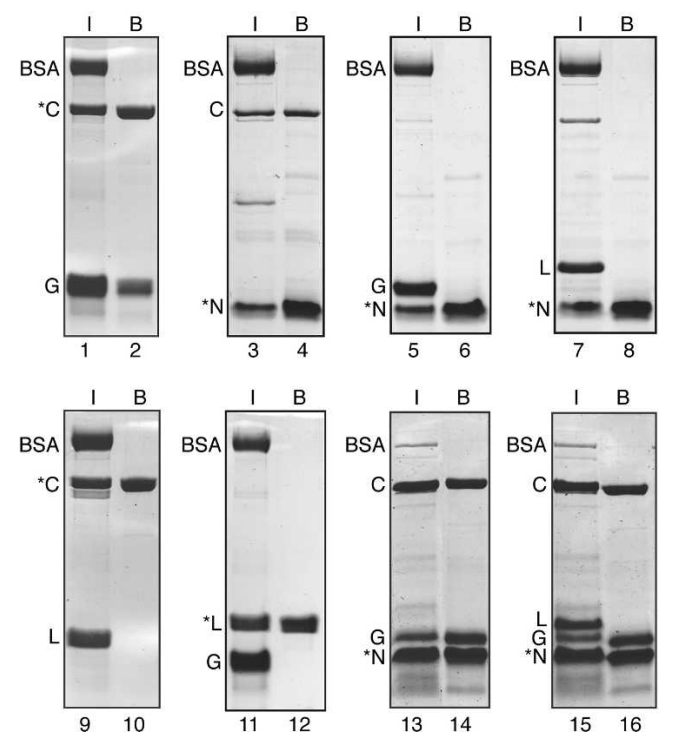

Figure 5. Cbf5 interacts with Gar1 and Nop10 to form a heterotrimeric protein complex. Combinations of the four H/ACA RNP proteins (indicated as C [Cbf5], L [L7Ae], G [Gar1], and N [Nop10]) were incubated in approximately equimolar amounts (I [input] lanes). In each panel the his-tagged protein is designated with an asterisk. Bovine serum albumin (BSA) was also added to the protein mixtures. The his-tagged proteins were purified using nickel agarose resin. Input (I lanes) and bound (B lanes) samples were compared following 15\% Tris-tricine gel electrophoresis and Coomassie blue staining. 
Baker et al.

Figure 6. Assembly of H/ACA RNP proteins with an $\mathrm{H} /$ ACA guide RNA. ${ }^{32}$ P-labeled wild-type (wt) or ACA mutant ( $\triangle$ ACA) Pf9 RNAs were incubated with one or more of the four proteins as indicated. The resultant RNP complexes were detected by native gel shift analysis followed by autoradiography. The distinct complex formed in the presence of all four proteins is indicated with an asterisk.
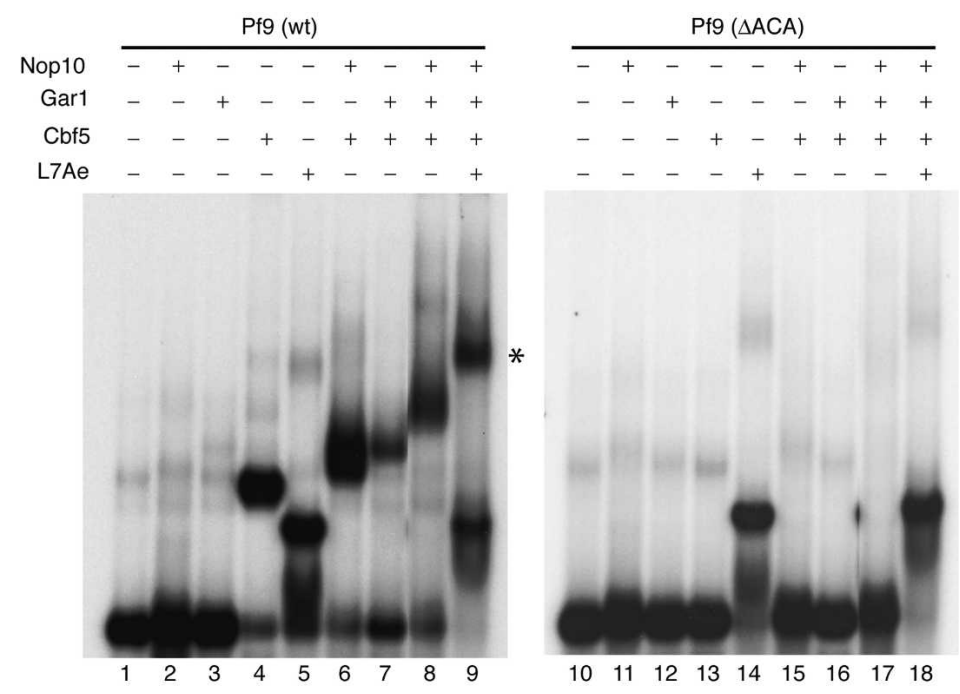

find evidence of interaction of L7Ae with the other proteins in the absence of the guide RNA (Fig. 5). Moreover, the interaction of the other proteins with the RNA did not depend on the presence of L7Ae (Fig. 6), indicating that L7Ae does not nucleate the assembly of the H/ACA RNP as it does the C/D RNP (Omer et al. 2002).

Cbf5 also interacts directly with the guide RNA and we found that box ACA, the pseudouridylation pocket, and the terminal loop of the hairpin appear to be important for this interaction (Figs. 2, 3), suggesting extensive contact between Cbf5 and the guide RNA. Our data indicate that Garl and Nop10 each interact directly with Cbf5, but not with the other proteins or with the guide RNA in the absence of Cbf5 (Figs. 2, 5). The interaction of Gar1 and Nop10 with Cbf5 mediates the interaction of these proteins with the complex (Fig. 6). Further, our results indicate that these three proteins can form a heterotrimeric Cbf5/Gar1/Nop10 complex that can interact

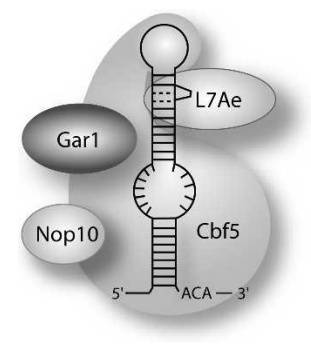

Figure 7. Organization of an archaeal pseudouridylation guide RNP complex. The results of this study suggest the model that is shown. L7Ae interacts directly with the K-turn of the guide RNA. Cbf5 also interacts directly and independently with the guide RNA, making extensive contacts that may include box ACA, the pseudouridylation pocket, and the terminal loop. Association of Garl and Nop10 with the complex is mediated by their individual interactions with Cbf5. Close contacts between the various components may occur in the context of the assembled RNP, but no evidence of additional independent interactions was obtained in this study. 
with the guide RNA (Figs. 5, 6; O.A. Youssef, R.M. Terns, and M.P. Terns, unpubl.). Based on our results it seems equally possible that these three proteins assemble on the guide RNA sequentially or as a preformed complex.

\section{Eukaryotic pseudouridylation guide RNPs}

The components of eukaryotic and archaeal pseudouridylation guide RNPs are generally well conserved, suggesting that the organization and function of the components will be fundamentally similar in the two systems. Unfortunately, detailed analysis of functional eukaryotic H/ACA RNPs has not been reported to date. However, two recent studies describe interactions between various components of eukaryotic H/ACA RNPs-one in a mammalian system and one in yeast (Henras et al. 2004; Wang and Meier 2004). The interactions observed in the yeast study (Henras et al. 2004) are in agreement with those reported here, while there are significant differences in the interactions observed in the mammalian system (Wang et al. 2000).

Using mammalian proteins expressed in rabbit reticulocyte lysates, Wang and Meier (2004) found a heterotrimeric protein complex with a different compositioncomprised of the mammalian homologs of Cbf5, Nop10, and L7Ae, rather than Cbf5, Nop10, and Gar1 (Fig. 5). In addition, they found that Nop10 is essential for interaction between the mammalian Cbf5 and L7Ae homologs, and thus appears to play the central role in this complex (Wang and Meier 2004), while Cbf5 is at the core of the archaeal complex, interacting independently with each Garl and Nop10 (Fig. 5). In the mammalian system, specific recognition of H/ACA RNAs required all three components of the trimeric complex (Wang and Meier 2004). On the other hand, we have found that archaeal Cbf5 interacts specifically with guide RNAs in the absence of the other proteins (Figs. 2-4), and that Garl and Nop10 do not observably increase the affinity of the interaction (data not shown).

On the other hand, the data from yeast suggest that the organization of the yeast H/ACA RNP resembles the archaeal complex. In studies with complexes expressed and assembled in vivo and purified from Saccharomyces cerevisiae, Henras et al. (2004) also found that Cbf5(p), Gar1(p), and Nop10(p) can form a complex independent of both L7Ae (Nhp2p) and guide RNA.

At present it is not clear whether the observed discrepancies between the mammalian system and the archaeal and yeast systems reflect fundamental differences in the RNPs or the limitations of experimental approaches. The authors of the mammalian study note that no significant pseudouridylase activity could be detected with the complexes assembled in the mammalian system (Wang and Meier 2004). The functionality of the purified yeast complexes was not reported. The eukaryotic H/ACA RNP proteins, and especially Cbf5, are challenging to express and purify (Wang et al. 2000; Henras et al. 2004). It is possible that both the lack of functionality of the mammalian proteins and the observed differences result from production of defective (perhaps misfolded) mammalian proteins in vitro. A better understanding of the extent of differences between the eukaryotic and archaeal RNPs awaits more detailed structural studies of functional eukaryotic complexes.

\section{Roles of the H/ACA RNP proteins in RNA-guided pseudouridylation}

All evidence indicates that Cbf5 is the pseudouridine synthase (i.e., catalyzes breakage of the N1-C1' glycosidic bond and reattachment of the free uridine base to the ribose via a $\mathrm{C} 5-\mathrm{Cl}^{\prime}$ glycosidic bond). The sequence and structure of the protein is very similar to other known pseudouridine synthases (Koonin 1996; Charette and Gray 2000; Hoang and Ferre-D'Amare 2001), and in yeast, mutation of the predicted catalytic aspartate (universally conserved in all pseudouridine synthases) prevents RNA-guided pseudouridylation in vivo (Lafontaine et al. 1998; Zebarjadian et al. 1999|. Our work establishes two additional key roles for Cbf5: direct recognition of the guide RNA and recruitment of both Gar1 and Nop10 (Figs. 2, 5).

What are the roles of the other proteins? It is clear that L7Ae interacts directly with the guide RNA (Fig. 2; Rozhdestvensky et al. 2003). In addition, our results indicate that L7Ae does not interact independently with the other proteins and is not responsible for the recruitment of the other proteins to the complex (Figs. 5, 6; data not shown). One conceivable role of L7Ae is alteration of the structure of the guide RNA (e.g., introduction of a kink in the upper stem) to induce a conformation in the RNA or RNP that is important for pseudouridylation.

Our finding that Cbf5 interacts directly with the guide RNA indicates that the other proteins do not bridge the interaction of the modifying enzyme with the guide RNA. Gar1 and Nop10 both interact with Cbf5 (Fig. 5), but this interaction does not apparently increase the affinity of Cbf5 for the guide RNA (data not shown). The association of Gar1 and Nop10 with Cbf5 suggests that they may serve auxiliary roles in H/ACA RNP function. For example, these proteins may promote or stabilize the interaction with the substrate rRNA, ensure proper positioning of the target uridine in the active site, or influence substrate rRNA release following catalysis. Sitespecific cross-linking studies support an intimate association of Garl (as well as Cbf5) with the target uridine in the mammalian system (Wang and Meier 2004). In addition, genetic depletion of Garl $(\mathrm{p})$ in yeast results in partially assembled RNP complexes that are unable to interact with substrate rRNA (Bousquet-Antonelli et al. 1997). Analysis of the sequence of archaeal Nop10 proteins suggests the potential existence of a zinc-finger motif (D. Baker, J. Omichinski, R. Terns, and M. Terns, unpubl.) and the ability to interact directly with nucleic acids-perhaps substrate RNA.

Importantly, our results establish for the first time that each of the four proteins is essential for RNA-guided pseudouridylation in vitro (Fig. 1). Previous studies in eukaryotes established that these proteins are associated 
with H/ACA guide RNAs and that RNA pseudouridylation is reduced in cells lacking these proteins. Our results indicate that the proteins are not solely required for the stability of the guide RNAs or other upstream functions in vivo, but are also necessary for efficient catalysis of the modification.

\section{Materials and methods}

\section{Expression and purification of recombinant proteins}

The genes encoding $P$. furiosus Cbf5 (PF1785), Gar1 (PF1791), Nop10 (PF1141), and L7Ae (PF1367) were amplified by PCR from genomic DNA and cloned into modified versions of pET21d and pET24d. The primers used in the PCR reactions are specified in Supplementary Tables 1 and 2. The recombinant proteins were expressed in Escherichia coli BL21 codon+ cells (DE3, Invitrogen). The cells were grown to a culture $\mathrm{OD}_{600}$ of 0.7 , and expression of the proteins was induced with $1 \mathrm{mM}$ isopropylthio- $\beta$-D-galactoside (IPTG) for $4 \mathrm{~h}$ at $37^{\circ} \mathrm{C}$. The cells were pelleted, resuspended in Buffer A $(20 \mathrm{mM}$ sodium phosphate buffer at $\mathrm{pH} 7.0,1 \mathrm{M} \mathrm{NaCl}$, and $0.1 \mathrm{mM}$ phenylmethylsulfonyl fluoride [PMSF]), and disrupted by sonication (10-sec pulse, 20-sec rest, repeated five cycles using a Branson Sonifier Cell Disruptor 200 and microtip, intensity level 6, duty cycle $60 \%$ ). The sonicated sample was centrifuged at $45,000 \times \mathrm{g}$ for $30 \mathrm{~min}$ at $4^{\circ} \mathrm{C}$. The supernatant was heated at $75^{\circ} \mathrm{C}-78^{\circ} \mathrm{C}$ for $20 \mathrm{~min}$ and centrifuged at $45,000 \times \mathrm{g}$ for $20 \mathrm{~min}$ at $4^{\circ} \mathrm{C}$. The supernatant was filtered $(0.8 \mu \mathrm{m}$ pore size Millex Filter Unit; Millipore) and applied to a Ni-NTA agarose (Qiagen) column equilibrated with Buffer A. Proteins were eluted with Buffer A containing 350-500 mM imidazole. The protein samples were dialyzed at room temperature against $40 \mathrm{mM}$ HEPES ( $\mathrm{pH} 7.0$ ), 100-500 mM KCl. Some samples were concentrated using a PL-10 Microcon filter device (Millipore). The purity of the protein samples was assessed by SDS-PAGE and Coomassie blue staining. The concentration of the proteins was determined via BCA protein assay (Pierce).

\section{Synthesis of DNA templates for in vitro transcription of RNAs}

DNA templates used for in vitro transcription of Pf3 and Pf9 RNAs (and mutants) were generated by PCR using $P$. furiosus genomic DNA and oligonucleotides as described in Supplementary Tables 1 and 2. The oligonucleotides incorporate an SP6 polymerase promoter for in vitro transcription. The PCR products were cloned into the pCR2.1-TOPO vector (Invitrogen) and were confirmed by DNA sequence analysis. DNA templates encoding sR2 and sR29 (Speckmann et al. 2002) and human

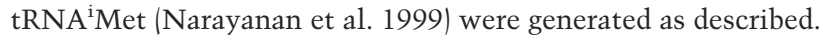
The template for in vitro transcription of the substrate RNA (corresponding to nucleotides 905-917 of $P$. furiosus 16S rRNA with uridines 915-917 replaced by adenosines, and flanked by three nucleotide extensions at each end) was generated by direct annealing of two oligonucleotides (see Supplementary Tables 1, 3).

\section{In vitro transcription of guide and target $R N A s$}

PCR product (30-100 ng), linearized plasmid (1 $\mu \mathrm{g})$, or annealed oligonucleotides were used as templates for in vitro transcription, which was performed as described previously (Narayanan et al. 1999) using $\alpha^{32}$ P-GTP to uniformly radiolabel guide RNAs or $\alpha^{32}$ P-UTP to label the uridine in the substrate rRNA.

\section{Pseudouridylation assay}

Guide RNA (0.2-5 pmol) and ${ }^{32}$ P-labeled rRNA substrate $(0.05$ pmol) were incubated with purified his-tagged proteins in $40 \mathrm{mM}$ HEPES (pH 7.0), $500 \mathrm{mM} \mathrm{KCl}, 1.5 \mathrm{mM} \mathrm{MgCl}_{2}, 10 \%$ (v/v) glycerol, $5 \mu \mathrm{g}$ E. coli tRNA, $1 \mathrm{U} / 10 \mu \mathrm{L}$ of RNasin (Promega) for $1 \mathrm{~h}$ at $70^{\circ} \mathrm{C}$. The reaction was terminated by extraction with phenol/chloroform/isoamyl alcohol at $4^{\circ} \mathrm{C}$, and the RNA was ethanol precipitated and digested with nuclease P1 (200 ng, United States Biological). The nucleotide 5' monophosphate mixture was separated via thin layer chromatography on cellulose polyethyleneimine plates (EMD Chemicals) with isopropanol-HCl-water (70:15:15) as the solvent (Yu et al. 2001). Under these conditions, pseudouridine migrates more slowly than uridine (Yu et al. 2001).

\section{Gel mobility shift assays}

${ }^{32}$ P-labeled RNA (0.05 pmol) was mock treated or mixed with indicated amounts of recombinant Cbf5, Nop10, L7Ae, or Gar1 proteins. Reactions were carried out in a final volume of $20 \mu \mathrm{L}$ containing $20 \mathrm{mM}$ HEPES (pH 7.0), $250 \mathrm{mM} \mathrm{KCl}, 1.5 \mathrm{mM}$ $\mathrm{MgCl}_{2}, 0.25 \mu \mathrm{g} / \mu \mathrm{L}$ E. coli tRNA, $0.75 \mathrm{mM} \mathrm{DTT}$, and $10 \%$ glycerol. After incubation at $37^{\circ} \mathrm{C}$ for $1 \mathrm{~h}$, samples were loaded on nondenaturing $6 \%$ or $8 \%$ polyacrylamide gels containing $0.5 \times \mathrm{TBE}$. Electrophoresis was performed at $4^{\circ} \mathrm{C}$ in $0.5 \times \mathrm{TBE}$ for $12 \mathrm{~h}$ at $125 \mathrm{~V}$. The RNA distribution was visualized by autoradiography after gel drying.

\section{In vitro protein/protein interaction assay}

Protein samples were dialyzed against Buffer B $(20$ mM HEPES at $\mathrm{pH} 7.0,500 \mathrm{mM} \mathrm{KCl}, 1.5 \mathrm{mM} \mathrm{MgCl}_{2}$ ). Approximately equimolar amounts of proteins were incubated for $30 \mathrm{~min}$ at $37^{\circ} \mathrm{C}$. Bovine serum albumin (Promega) was included as a negative control. Half of the protein mixture was reserved as input sample and concentrated 10-fold using a YM-3 Microcon filter device (Millipore). The other half of the sample was incubated for $10 \mathrm{~min}$ at room temperature with $15 \mu \mathrm{L}$ of Ni-NTA resin (Qiagen) equilibrated in Buffer B. The resin was washed four times with Buffer B plus $20 \mathrm{mM}$ imidazole and $0.1 \%$ Triton $\mathrm{X}-100$. Bound proteins were eluted with SDS gel loading buffer and heating. Input and bound protein samples were analyzed by $15 \%$ Tris-tricine gel electrophoresis and Coomassie blue protein staining.

\section{Acknowledgments}

We are grateful to Mike Adams, Gerti Schut, and Frank Jenney (University of Georgia) for generously sharing P. furiosus resources; Yi-Tao Yu (University of Rochester) and Tom Meier (Albert Einstein College of Medicine) for technical advice regarding the pseudouridylation assay; Natalia Starostina for technical insights on protein expression; and Sarah Marshburn for characterization of $\mathrm{Pf} 9$ and critical reading of this manuscript. This work was supported by grants from the National Institutes of Health and National Science Foundation to M.P.T. and R.M.T, a fellowship from the Egyptian government to O.A.Y., and a CURO Summer Research Fellowship to M.I.R.C.

\section{References}

Aittaleb, M., Rashid, R., Chen, Q., Palmer, J.R., Daniels, C.J., and Li, H. 2003. Structure and function of archaeal box C/D sRNP core proteins. Nat. Struct. Biol. 10: 256-263. 
Ambros, V. 2004. The functions of animal microRNAs. Nature 431: 350-355.

Aravind, L. and Koonin, E.V. 2001. THUMP-A predicted RNAbinding domain shared by 4-thiouridine, pseudouridine synthases and RNA methylases. Trends Biochem. Sci. 26: 215217.

Bachellerie, J.-P. and Cavaille, J. 1998. Small nucleolar RNAs guide the ribose methylations of eukaryotic rRNAs. In Modification and editing of RNA (eds. H. Grosjean and B. Benne), pp. 255-272. ASM Press, Washington, DC.

Balakin, A.G., Smith, L., and Fournier, M.J. 1996. The RNA world of the nucleolus: Two major families of small RNAs defined by different box elements with related functions. Cell 86: 823-834.

Bartel, D.P. 2004. MicroRNAs: Genomics, biogenesis, mechanism, and function. Cell 116: 281-297.

Bortolin, M.L., Ganot, P., and Kiss, T. 1999. Elements essential for accumulation and function of small nucleolar RNAs directing site-specific pseudouridylation of ribosomal RNAs. EMBO J. 18: 457-469.

Bousquet-Antonelli, C., Henry, Y., Gelugne, J.P., CaizerguesFerrer, M., and Kiss, T. 1997. A small nucleolar RNP protein is required for pseudouridylation of eukaryotic ribosomal RNAs. EMBO J. 16: 4770-4776.

Cavaille, J., Nicoloso, M., and Bachellerie, J.P. 1996. Targeted ribose methylation of RNA in vivo directed by tailored antisense RNA guides. Nature 383: 732-735.

Cavaille, J., Buiting, K., Kiefmann, M., Lalande, M., Brannan, C.I., Horsthemke, B., Bachellerie, J.P., Brosius, J., and Huttenhofer, A. 2000. Identification of brain-specific and imprinted small nucleolar RNA genes exhibiting an unusual genomic organization. Proc. Natl. Acad. Sci. 97: 1431114316.

Charette, M. and Gray, M.W. 2000. Pseudouridine in RNA: What, where, how, and why. IUBMB Life 49: 341-351.

Charron, C., Manival, X., Clery, A., Senty-Segault, V., Charpentier, B., Marmier-Gourrier, N., Branlant, C., and Aubry, A. 2004. The archaeal sRNA binding protein L7Ae has a 3D structure very similar to that of its eukaryal counterpart while having a broader RNA-binding specificity. J. Mol. Biol. 342: 757-773.

Darzacq, X., Jady, B.E., Verheggen, C., Kiss, A.M., Bertrand, E., and Kiss, T. 2002. Cajal body-specific small nuclear RNAs: A novel class of 2'-O-methylation and pseudouridylation guide RNAs. EMBO J. 21: 2746-2756.

Decatur, W.A. and Fournier, M.J. 2003. RNA-guided nucleotide modification of ribosomal and other RNAs. J. Biol. Chem. 278: 695-698.

Donmez, G., Hartmuth, K., and Luhrmann, R. 2004. Modified nucleotides at the $5^{\prime}$ end of human U2 snRNA are required for spliceosomal E-complex formation. RNA 10: 1925-1933.

Dragon, F., Pogacic, V., and Filipowicz, W. 2000. In vitro assembly of human H/ACA small nucleolar RNPs reveals unique features of U17 and telomerase RNAs. Mol. Cell. Biol. 20: 3037-3048.

Filipowicz, W. and Pogacic, V. 2002. Biogenesis of small nucleolar ribonucleoproteins. Curr. Opin. Cell. Biol. 14: 319-327.

Ganot, P., Bortolin, M.L., and Kiss, T. 1997a. Site-specific pseudouridine formation in preribosomal RNA is guided by small nucleolar RNAs. Cell 89: 799-809.

Ganot, P., Caizergues-Ferrer, M., and Kiss, T. 1997b. The family of box ACA small nucleolar RNAs is defined by an evolutionarily conserved secondary structure and ubiquitous sequence elements essential for RNA accumulation. Genes \& Dev 11: 941-956.

He, L. and Hannon, G.J. 2004. MicroRNAs: Small RNAs with a big role in gene regulation. Nat. Rev. Genet. 5: 522-531.

Heiss, N.S., Knight, S.W., Vulliamy, T.J., Klauck, S.M., Wiemann, S., Mason, P.J., Poustka, A., and Dokal, I. 1998. $\mathrm{X}$-linked dyskeratosis congenita is caused by mutations in a highly conserved gene with putative nucleolar functions. Nat. Genet. 19: 32-38.

Henras, A., Henry, Y., Bousquet-Antonelli, C., NoaillacDepeyre, J., Gelugne, J.P., and Caizergues-Ferrer, M. 1998. Nhp2p and Nop10p are essential for the function of H/ACA snoRNPs. EMBO J. 17: 7078-7090.

Henras, A.K., Capeyrou, R., Henry, Y., and Caizergues-Ferrer, M. 2004. Cbf5p, the putative pseudouridine synthase of H/ACA-type snoRNPs, can form a complex with Garlp and Nop10p in absence of Nhp2p and box H/ACA snoRNAs. RNA 10: 1704-1712.

Hoang, C. and Ferre-D'Amare, A.R. 2001. Cocrystal structure of a tRNA Psi55 pseudouridine synthase: Nucleotide flipping by an RNA-modifying enzyme. Cell 107: 929-939.

Jiang, W., Middleton, K., Yoon, H.J., Fouquet, C., and Carbon, J. 1993. An essential yeast protein, CBF5p, binds in vitro to centromeres and microtubules. Mol. Cell. Biol. 13: 48844893.

King, T.H., Liu, B., McCully, R.R., and Fournier, M.J. 2003. Ribosome structure and activity are altered in cells lacking snoRNPs that form pseudouridines in the peptidyl transferase center. Mol. Cell 11: 425-435.

Kiss, T. 2002. Small nucleolar RNAs: An abundant group of noncoding RNAs with diverse cellular functions. Cell 109: $145-148$.

Kiss-Laszlo, Z., Henry, Y., Bachellerie, J.P., Caizergues-Ferrer, M., and Kiss, T. 1996. Site-specific ribose methylation of preribosomal RNA: A novel function for small nucleolar RNAs. Cell 85: 1077-1088.

Klein, D.J., Schmeing, T.M., Moore, P.B., and Steitz, T.A. 2001. The kink-turn: A new RNA secondary structure motif. EMBO I. 20: 4214-4221.

Klein, R.J., Misulovin, Z., and Eddy, S.R. 2002. Noncoding RNA genes identified in AT-rich hyperthermophiles. Proc. Natl. Acad. Sci. 99: 7542-7547.

Koonin, E.V. 1996. Pseudouridine synthases: Four families of enzymes containing a putative uridine-binding motif also conserved in dUTPases and dCTP deaminases. Nucleic Acids Res. 24: 2411-2415.

Kuhn, J.F., Tran, E.J., and Maxwell, E.S. 2002. Archaeal ribosomal protein $\mathrm{L} 7$ is a functional homolog of the eukaryotic $15.5 \mathrm{kD} /$ Snu $13 \mathrm{p}$ snoRNP core protein. Nucleic Acids Res. 30: 931-941.

Lafontaine, D.L., Bousquet-Antonelli, C., Henry, Y., Caizergues-Ferrer, M., and Tollervey, D. 1998. The box H + ACA snoRNAs carry Cbf5p, the putative rRNA pseudouridine synthase. Genes \& Dev 12: 527-537.

Maden, B.E. 1990. The numerous modified nucleotides in eukaryotic ribosomal RNA. Prog. Nucleic Acid Res. Mol. Biol. 39: 241-303.

Meier, U.T. and Blobel, G. 1994. NAP57, a mammalian nucleolar protein with a putative homolog in yeast and bacteria. J. Cell. Biol. 127: 1505-1514.

Narayanan, A., Speckmann, W., Terns, R., and Terns, M.P. 1999. Role of the box C/D motif in localization of small nucleolar RNAs to coiled bodies and nucleoli. Mol. Biol. Cell 10: $2131-2147$.

Ofengand, J. and Fournier, M.J. 1998. The pseudouridine residues of rRNA: Number, location, biosynthesis, and function. In Modification and editing of RNA (eds. H. Grosjean and B. Benne), pp. 229-253. ASM Press, Washington, DC.

Ofengand, J., Malhotra A., Remme, J., Gutgsell, N.S., Del 
Baker et al.

Campo, M., Jean-Charles, S., Peil, L., and Kaya, Y. 2001. Pseudouridines and pseudouridine synthases of the ribosome. Cold Spring Harbor Symp. Quant. Biol. 66: 147-159.

Omer, A.D., Lowe, T.M., Russell, A.G., Ebhardt, H., Eddy, S.R., and Dennis, P.P. 2000. Homologs of small nucleolar RNAs in Archaea. Science 288: 517-522.

Omer, A.D., Ziesche, S., Ebhardt, H., and Dennis, P.P. 2002. In vitro reconstitution and activity of a C/D box methylation guide ribonucleoprotein complex. Proc. Natl. Acad. Sci. 99: 5289-5294.

Omer, A.D., Ziesche, S., Decatur, W.A., Fournier, M.J., and Dennis, P.P. 2003. RNA-modifying machines in archaea. Mol. Microbiol. 48: 617-629.

Rashid, R., Aittaleb, M., Chen, Q., Spiegel, K., Demeler, B., and $\mathrm{Li}, \mathrm{H}$. 2003. Functional requirement for symmetric assembly of archaeal box C/D small ribonucleoprotein particles. J. Mol. Biol. 333: 295-306.

Richard, P., Darzacq, X., Bertrand, E., Jady, B.E., Verheggen, C., and Kiss, T. 2003. A common sequence motif determines the Cajal body-specific localization of box H/ACA scaRNAs. EMBO J. 22: 4283-4293.

Rozhdestvensky, T.S., Tang, T.H., Tchirkova, I.V., Brosius, J., Bachellerie, J.P., and Huttenhofer, A. 2003. Binding of L7Ae protein to the K-turn of archaeal snoRNAs: A shared RNA binding motif for C/D and H/ACA box snoRNAs in Archaea. Nucleic Acids Res. 31: 869-877.

Speckmann, W.A., Li, Z.H., Lowe, T.M., Eddy, S.R., Terns, R.M., and Terns, M.P. 2002. Archaeal guide RNAs function in rRNA modification in the eukaryotic nucleus. Curr. Biol. 12: 199-203.

Tang, T.H., Bachellerie, J.P., Rozhdestvensky, T., Bortolin, M.L., Huber, H., Drungowski, M., Elge, T., Brosius, J., and Huttenhofer, A. 2002. Identification of 86 candidates for small non-messenger RNAs from the archaeon Archaeoglobus fulgidus. Proc. Natl. Acad. Sci. 99: 7536-7541.

Terns, M.P. and Terns, R.M. 2002. Small nucleolar RNAs: Versatile trans-acting molecules of ancient evolutionary origin. Gene Expr. 10: 17-39.

Tran, E.J., Zhang, X., and Maxwell, E.S. 2003. Efficient RNA 2 '-O-methylation requires juxtaposed and symmetrically assembled archaeal box $\mathrm{C} / \mathrm{D}$ and $\mathrm{C}^{\prime} / \mathrm{D}^{\prime}$ RNPs. EMBO $J$. 22: 3930-3940.

Vitali, P., Royo, H., Seitz, H., Bachellerie, J.P., Huttenhofer, A., and Cavaille, J. 2003. Identification of 13 novel human modification guide RNAs. Nucleic Acids Res. 31: 6543-6551.

Wang, C. and Meier, U.T. 2004. Architecture and assembly of mammalian H/ACA small nucleolar and telomerase ribonucleoproteins. EMBO J. 23: 1857-1867.

Wang, H., Boisvert, D., Kim, K.K., Kim, R., and Kim, S.H. 2000. Crystal structure of a fibrillarin homologue from Methanococcus jannaschii, a hyperthermophile, at $1.6 \mathrm{~A}$ resolution. EMBO J. 19: 317-323.

Watanabe, Y. and Gray, M.W. 2000. Evolutionary appearance of genes encoding proteins associated with box H/ACA snoRNAs: cbf5p in Euglena gracilis, an early diverging eukaryote, and candidate Garlp and Nop10p homologs in archaebacteria. Nucleic Acids Res. 28: 2342-2352.

Watkins, N.J., Gottschalk, A., Neubauer, G., Kastner, B., Fabrizio, P., Mann, M., and Luhrmann, R. 1998. Cbf5p, a potential pseudouridine synthase, and Nhp2p, a putative RNA-binding protein, are present together with Garlp in all $\mathrm{H} \mathrm{BOX}$ / ACA-motif snoRNPs and constitute a common bipartite structure. RNA 4: 1549-1568.

Watkins, N.J., Segault, V., Charpentier, B., Nottrott, S., Fabrizio, P., Bachi, A., Wilm, M., Rosbash, M., Branlant, C., and Luhrmann, R. 2000. A common core RNP structure shared between the small nucleoar box C/D RNPs and the spliceosomal U4 snRNP. Cell 103: 457-466.

Yu, Y.T., Shu, M.D., and Steitz, J.A. 1998. Modifications of U2 snRNA are required for snRNP assembly and pre-mRNA splicing. EMBO J. 17: 5783-5795.

Yu, Y.T., Shu, M.D., Narayanan, A., Terns, R.M., Terns, M.P., and Steitz, J.A. 2001. Internal modification of U2 small nuclear (sn)RNA occurs in nucleoli of Xenopus oocytes. J. Cell. Biol. 152: 1279-1288.

Yu, Y.T., Terns, R.M., and Terns, M.P. 2005. Mechanisms and functions of RNA-guided RNA modification. In Fine-tuning of RNA functions by modification and editing. Topics in current genetics Vol. 12 (ed. H. Grosjean), pp. 223-262. Springer-Verlag, New York.

Zebarjadian, Y., King, T., Fournier, M.J., Clarke, L., and Carbon, J. 1999. Point mutations in yeast CBF5 can abolish in vivo pseudouridylation of rRNA. Mol. Cell. Biol. 19: 7461-7472.

Zhao, X. and Yu, Y.T. 2004. Pseudouridines in and near the branch site recognition region of U2 snRNA are required for snRNP biogenesis and pre-mRNA splicing in Xenopus oocytes. RNA 10: 681-690. 


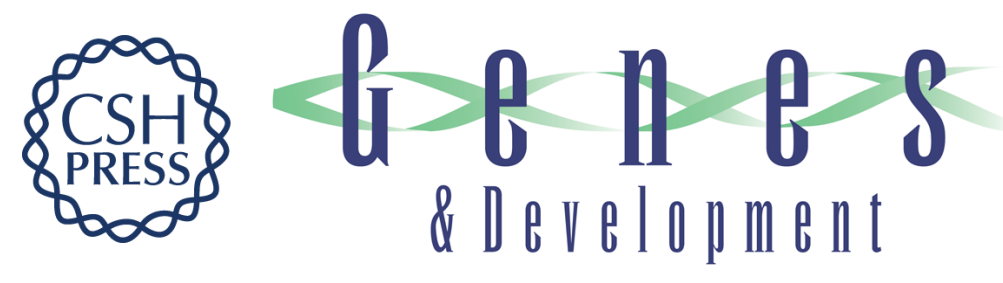

\section{RNA-Guided RNA modification: functional organization of the archaeal H/ACA RNP}

Daniel L. Baker, Osama A. Youssef, Michael I.R. Chastkofsky, et al.

Genes Dev. 2005, 19:

Access the most recent version at doi:10.1101/gad.1309605

\section{Supplemental http://genesdev.cshlp.org/content/suppl/2005/05/04/gad.1309605.DC1 Material}

References This article cites 57 articles, 27 of which can be accessed free at: http://genesdev.cshlp.org/content/19/10/1238.full.html\#ref-list-1

\section{License}

Email Alerting

Receive free email alerts when new articles cite this article - sign up in the box at the top Service 